\title{
Catalyst-assisted DBD plasma for coupling of methane: Minimizing carbon- deposits by structured reactors
}

\author{
Nuria García-Moncada ${ }^{\mathrm{a}}$, Gerard van Rooij ${ }^{\mathrm{b}}$, Toine Cents ${ }^{\mathrm{c}}$, Leon Lefferts ${ }^{\mathrm{a}, *}$ \\ ${ }^{a}$ Catalytic Processes and Materials (CPM), TNW Faculty, University of Twente, 7522 NB, Enschede, The Netherlands \\ ${ }^{\mathrm{b}}$ Nonequilibrium Fuel Conversion, DIFFER, 5612 AJ, Eindhoven, The Netherlands \\ ' Sasol Technology Netherlands B.V., 7544 GG, Enschede, The Netherlands
}

\section{A R T I C L E I N F O}

\section{Keywords:}

DBD plasma

Structured reactor

Methane coupling

Plasma-catalysis

Carbon deposits

\begin{abstract}
A B S T R A C T
Non-oxidative coupling of methane has been performed in DBD plasma reactors with a catalytic layer with varying thickness loaded on the reactor wall. These structured reactors allow to study the effect of the thickness of the catalyst layer, including the blank plasma reactor, without significant modification of plasma properties, SEI and residence time. Moreover, it allows analysis of the catalytic effect of $\mathrm{Pd} / \mathrm{Al}_{2} \mathrm{O}_{3}$. The catalyst layer decreases the methane conversion only mildly, which is attributed to hydrogenation of $\mathrm{CH}_{\mathrm{x}}$ radicals at the outer surface of the catalyst layer. This results in typically $34 \%$ methane conversion at $2.8 \mathrm{~W}$ at room temperature with $6 \% \mathrm{CH}_{4}$ in $\mathrm{Ar}$, independently of the layer thickness. In contrast, the thickness of the catalyst layer strongly influences the product distribution, assigned to hydrogenation of acetylenes at external and internal surfaces in the catalyst layer. The formation of undesired deposits is suppressed by a factor of 2 with value-added hydrocarbons selectivity of $70 \%$ and a carbon balance of $93 \%$. In addition, catalytic-wall reactors was compared with packed bed reactors. The synergistic effect is much more evident in the structured reactor than in the packed bed reactor, independently of the position of the catalytic bed.
\end{abstract}

\section{Introduction}

The depletion of mineral oil resources and the available large natural gas reserves rich in $\mathrm{CH}_{4}$ have promoted interest in developing efficient and economical viable processes for methane conversion to high value-added chemicals in the last century [1,2]. More recently, interest revived caused by the development of shale gas, especially in the USA. The direct conversion of methane by coupling reaction is challenging as methane is a very stable molecule. Two main approaches have been extensively studied: oxidative and non-oxidative coupling of methane $[3,4]$. The former noticeably increases the methane conversion but strongly decreases the selectivity to desired hydrocarbons, caused by consecutive deep oxidation to $\mathrm{CO}$ and $\mathrm{CO}_{2}$. The latter is highly limited by thermodynamics, resulting in low conversion despite high operation temperatures ( $>600^{\circ} \mathrm{C}$ ), as well as extensive carbon formation. In this context, several catalysts have been studied in order to achieve high selectivity to desired products at high methane conversion levels [3-9]. Despite the favorable results reported by Bao et al. [5], it appears difficult to reproduce the results without significant carbon formation and unfortunately the amount of carbon formed is not always reported.
Non-oxidative coupling of methane in a non-equilibrium plasma, generated in a dielectric barrier discharge (DBD) reactor at temperatures close to ambient, might be a promising alternative. Such a nonequilibrium plasma contains accelerated electrons with high energy ( $10^{3}-10^{4} \mathrm{~K}$ ) capable of activating methane molecules by electrons impact, creating radicals $\left(\mathrm{CH}_{4}+e^{-} \rightarrow \cdot \mathrm{CH}_{3}+\cdot \mathrm{H}+e^{-}\right)$[10]. In contrast, excitation of rotation and translation of molecules in a DBD is very limited, implying that the temperature of the gas remains close to room temperature $[10,11]$. Therefore, coupling of methane reaction in absence of oxygen has been studied at mild temperatures [10,12-14]. The plasma-driven reaction can provide high methane conversion depending on the reactor design, the discharge power and the feed composition (pure or diluted methane, or additives like $\mathrm{H}_{2}$ or $\mathrm{H}_{2} \mathrm{O}$ ) [15-19]. However, as plasma activates methane via formation of radicals, the selectivity to desired products is still uncontrolled. Formation of several linear or branched hydrocarbons have been reported, usually from $\mathrm{C}_{2}$ to $\mathrm{C}_{6}$, depending mainly on the power and the feed composition [20-22]. Moreover, formation of carbonaceous deposits is significant and increases with increasing conversion. For instance, Indarto et al. [22] reported formation of carbonaceous deposits on the

\footnotetext{
* Corresponding author.

E-mail addresses: n.garciamoncada@utwente.nl (N. García-Moncada), G.J.vanRooij@differ.nl (G. van Rooij), Toine.Cents@de.sasol.com (T. Cents), 1.lefferts@utwente.nl (L. Lefferts).
} 
wall of a DBD plasma reactor causing deactivation, even under favorable conditions to minimize carbon formation at methane conversion as low as $13.8 \%$. Kudryashov et al. reported that co-feeding $\mathrm{H}_{2} \mathrm{O}$ prevented formation of deposits at low methane conversion of about $10 \%$ [23], at the expense of formation of oxygenated products like methanol and acetone in addition to alkanes and olefins.

The formation of carbon increases when increasing conversion [14,24-27], e.g. by increasing the specific energy input (SEI, power discharge per mol of methane fed) or diluting the methane with an inert gas like Ar, enhancing the methane activation by Penning effect [28]. However, most papers report only the selectivity to desired hydrocarbons, without explicitly considering the carbon balance and carbon formation. In contrast, Jo et al. [17,19,29] reported poor carbon balance of 70-75 \% at $20 \% \mathrm{CH}_{4}$ conversion in different noble gases. Wang et al. [16] studied methane conversion and the selectivity to carbon deposits at different reactor conditions (residence time, power, discharge gap) at typically $20 \%$ conversion. The formation of carbon was measured by weighing the reactor before and after the experiment but unfortunately, the carbon balance was still below $70 \%$.

Combining plasma and catalysis seems to be a promising approach in which the catalyst can contribute to methane activation and/or selectivity to desired hydrocarbons, decreasing the formation of deposits $[10,30]$. However, combining catalysis and plasma is rather complex [31-34]. Introduction of a packed bed in the reactor changes the local linear velocity and thus the residence time, complicating the comparison and analysis of the effect of the catalyst. Even in the case that the overall plasma power remains constant, the energy density of the plasma will increase because the free volume, in which plasma is generated, is smaller in a packed bed reactor. Furthermore, the introduction of a packed bed in a DBD plasma influences the local electrical field because it also acts as a dielectric material, changing the electron energy distribution and the chemistry taking place in the plasma. In that respect, the morphology and shape of the particles have a remarkable influence on the plasma, as the electrical field is enhanced at sharp features and contact points between particles [35-38]. The catalyst and the plasma influence each other mutually in even more complex ways, including formation of microdischarges, changes in the discharge type, changes in the catalyst surface area, hot spot formation and changes in the catalytic surface properties [31,32,36,39-41]. Also, activated species in the plasma, including radicals and ions, electronic excited species and vibrational excited species, may chemisorb and react on the catalyst surface. This is further complicated by the fact that plasma cannot form inside pores smaller than typically $1 \mu \mathrm{m}[42,43]$, implying that the internal surface of the catalyst cannot contribute in contrast to the external surface area. Therefore, small catalyst particles would maximize the effect of the catalyst, although too small particle sizes would cause high pressure drop and destabilization of the plasma [44]. Hence, introduction of pellets in the DBD plasma reactor can result both in synergy as well as in suppression of conversion [45].

Several studies on non-oxidative coupling of methane in DBD plasma reactors used packed beds of catalytically inert materials with different sizes and shapes, acting mainly as dielectric material $[36,46,47]$. Catalytically inert packed beds mainly alter power dissipation in the plasma and characteristic of the discharge, with varying influence on conversion, whereas the hydrocarbon product distribution is not significantly influenced. Kim et al. [36] observed that methane conversion decreases with increasing internal surface area, whereas Jo et al. [47] reported the opposite effect when comparing low surface area $\alpha-\mathrm{Al}_{2} \mathrm{O}_{3}$ with high surface area $\mathrm{\gamma}-\mathrm{Al}_{2} \mathrm{O}_{3}$ at the same conditions. However, high conversion promotes formation of deposits.

Only a few studies report on non-oxidative coupling of methane in a DBD reactor using a packed bed with catalytic activity. Jo et al. [29] used a planar DBD reactor, comparing the performance with $\mathrm{Pt} / \mathrm{Al}_{2} \mathrm{O}_{3}$ and $\mathrm{Al}_{2} \mathrm{O}_{3}$ only. The presence of $\mathrm{Pt}$ decreased the conversion slightly while the product distribution shifts to more saturated hydrocarbons, which was attributed to lowering the electric field in the presence of Pt.
Surprisingly, the catalytic activity of Pt for hydrogenation reactions was not considered. Górska and co-workers [48] studied the non-oxidative coupling of methane on $\mathrm{Cu} / \mathrm{ZnO} / \mathrm{Al}_{2} \mathrm{O}_{3}$ pellets in a $\mathrm{DBD}$ reactor at $240^{\circ} \mathrm{C}$ and compared the results with the blank reactor and a glass packed bed DBD reactor. However, the differences in conversion and selectivity observed in the three systems are small and the power discharge, formation of carbon deposits and the carbon balance are not reported; so it remains unclear whether any catalytic effect occurred.

The goal of this work is to decrease the formation of carbonaceous deposits during methane coupling by introducing a hydrogenation catalyst $\left(\mathrm{Pd} / \mathrm{Al}_{2} \mathrm{O}_{3}\right)$ in a DBD reactor. In order to facilitate interpretation of the experimental observations, catalytic-wall-reactors are used in this study, minimizing the influence of the catalyst on the plasma compared to a packed bed. Application of a thin catalyst layer allows introduction of the catalyst in the plasma reactor without changing significantly the plasma power, the SEI as well as the residence time as the volume of the catalyst much smaller than te volume of the plasma zone. This approach to disentangle the effect of plasma and catalyst has not been applied before, to the best of our knowledge.

\section{Experimental}

The tests were carried out in a home-made DBD plasma reactor at atmospheric pressure and room temperature, using an AC voltage supplier (PVM/DDR Plasma Driver GME PM89 CLASS 2.5) connected to coaxial stainless steel electrodes and a quartz tube reactor as dielectric material. The stainless-steel cylinder of $3.3 \mathrm{~cm}$ in length enclosing the quartz reactor tube ( $4 \mathrm{~mm}$ in inner diameter and $30 \mathrm{~cm}$ in length) was used as ground-voltage (GV) electrode. The stainless-steel rod of $1.6 \mathrm{~mm}$ in diameter as high-voltage (HV) electrode was placed in the center of the quartz reactor, resulting in a gap of $1.2 \mathrm{~mm}$ between the $\mathrm{HV}$ electrode and the inner wall of the reactor. The discharge power in the reactor was calculated from Q-V Lissajous plots [49,50]. The data were collected by a high voltage probe (TESTEC TT-HVP15 HF) and a $3.9 \mathrm{nF}$ capacitor and a probe linked to the grounded electrode (TESTEC TT-HV 250) both connected to an oscilloscope (Pico Scope 2000 series) as is illustrated in Fig. 1.

Coupling of methane was carried out at $2.8 \mathrm{~W}$ discharge power at $23 \mathrm{kHz}$ in all experiments. The input peak-to-peak voltage was varied in the window between 6.6 and $7.4 \mathrm{kV}$ range in order to operate at same discharge power in all experiments. A mixture of $6 \% \mathrm{CH}_{4}$ in Ar was fed at $20 \mathrm{ml} / \mathrm{min}$ in the plasma reactor at room temperature. The specific energy input $\left(3423 \mathrm{~kJ} / \mathrm{mol} \mathrm{CH}_{4}\right)$ with a residence time of $1 \mathrm{~s}$ in the discharge volume was kept constant. The gas products were analysed with an online Varian 450 GC equipped with TCD and FID detectors. Hayesep T\&Q, Molsieve 13x and PoraBOND Q columns were used to separate $\mathrm{C}_{2}, \mathrm{C}_{3}$ and $\mathrm{C}_{4}$ hydrocarbons, $\mathrm{H}_{2}$ and the unconverted $\mathrm{CH}_{4}$ gases. The methane conversion and the carbon-based selectivities were

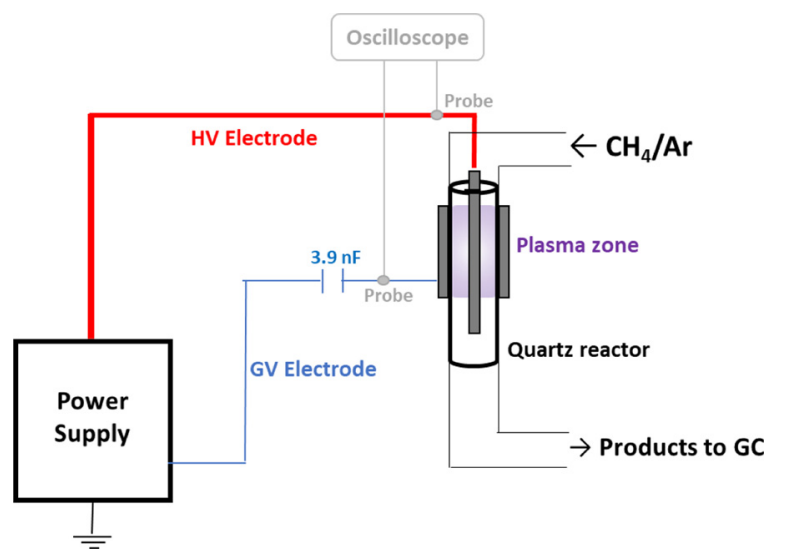

Fig. 1. Scheme of the DBD plasma setup. 
determined as follows:

$\operatorname{Conv}_{\mathrm{CH}_{4}}(\%)=\frac{n_{\mathrm{CH}_{4}}^{I N}-n_{\mathrm{CH}_{4}}^{O U T}}{n_{C H_{4}}^{I N}} \cdot 100$

$S_{C_{x} H_{y}}(\%)=\frac{x \cdot n_{C_{x} H_{y}}}{n_{C H_{4}}^{I N}-n_{C H_{4}}^{O U T}} \cdot 100$

$S_{H_{2}}(\%)=\frac{\frac{1}{2} \cdot n_{H_{2}}}{n_{C_{4}}^{I N}-n_{C H_{4}}^{O U T}} \cdot 100$

$S_{C_{D e p}}(\%)=100-\sum S_{C_{x} H_{y}}$

Where $n_{i}$ is the molar concentration of each compound (hydrocarbons or hydrogen) and $x$ is the number of carbon atoms in $\mathrm{C}_{\mathrm{x}} \mathrm{H}_{\mathrm{y}}$. In these calculations any difference in the ingoing and outgoing molar flowrate is small and can be denied. The selectivity to carbonaceous deposits as function of time-on-stream is estimated based on the carbon balance (Eq. (4)), assuming that the missing carbon is due to exclusively formation of deposits. Any possible error caused by formation of any unmeasured higher hydrocarbons $\left(\mathrm{C}_{4}{ }^{+}\right)$is disregarded in this calculation since the GC signals of these compounds were too small for quantification.

In addition, the averaged selectivity to deposits during an experiment of typically $3 \mathrm{~h}$ is determined by weighing the electrode and the reactor before and after the experiment, allowing calculation of the amount of deposits with an accuracy of $\pm 0.1 \mathrm{mg}$. The $\mathrm{C}$ and $\mathrm{H}$ content in the yellowish deposits formed on wall of the quartz tube is calculated based on CHN elemental analysis (Organic Elemental Analyzer, Flash 2000, Thermo Fisher Scientific Inc.). The averaged selectivity to deposits is then calculated as:

$S_{\text {Dep.Average }}(\%)=\frac{\left(n_{C_{E}}\right)+\left(n_{C_{Q}}\right)}{\left(\operatorname{Conv}_{\mathrm{CH}_{4}}\right)_{A v g} \cdot F_{C_{4}} \cdot t} \cdot 100$

Where $\mathrm{n}_{\mathrm{CE}}$ and $\mathrm{n}_{\mathrm{CQ}}$ are the number of moles carbon deposited on the electrode surface and the number of moles $\mathrm{C}$ in the polymeric deposit on the quartz wall after $3 \mathrm{~h}$ of reaction as calculated based on weight and elemental analysis, respectively. $\left(\mathrm{Conv}_{\mathrm{CH} 4}\right)_{\mathrm{Avg}}$ is the average conversion after $3 \mathrm{~h}$ of reaction, $\mathrm{F}_{\mathrm{CH} 4}$ is the inlet molar flow rate of methane and $t$ is the reaction time $(3 \mathrm{~h})$. Hydrogen and carbon balances were calculated based on the amount of deposits detected combined with the integrated amounts of products and unconverted methane as determined by GC during the 3 -h experiment:

$C_{B a l}=\frac{\sum\left(x \cdot F_{C_{x} H_{y}}^{\text {out }}\right)+\left({ }^{n} C_{E} / t\right)+\left({ }^{n}{ }_{C Q / t}\right)}{F_{C H_{4}}^{\text {in }}}$

$H_{B a l}=\frac{\sum\left(y \cdot F_{C_{x} H_{y}}^{\text {out }}\right)+\left(1.7 \cdot{ }^{n_{C Q} / t}\right)}{4 \cdot F_{C H_{4}}^{\text {in }}}$

Where the summation of molar flows out in the gas phase also includes the unconverted methane and the factor 1.7 in Eq. (7) is obtained from elemental analysis of the yellowish deposits.

The empty reactor (blank), structured reactors with thin catalytic layers and packed bed reactors (Fig. 2) were tested under the same reaction conditions. Thin catalyst layers were prepared via washcoating of the internal wall, using a colloidal suspension with $14 \mathrm{wt} . \%$ of commercial $\mathrm{Pd} / \mathrm{\gamma}-\mathrm{Al}_{2} \mathrm{O}_{3}$ catalyst ( $1 \mathrm{wt} . \% \mathrm{Pd}$, Alfa Aesar, particles smaller than $32 \mu \mathrm{m}$ via sieving), $6 \mathrm{wt}$.\% of colloidal alumina (20 wt.\% $\mathrm{Al}_{2} \mathrm{O}_{3}$ in water, Alfa Aesar) and distillated water. The desired position and size of the catalytic wall in the tube was achieved by wetting a part of the internal wall, controlled by quartz wool at the bottom and the amount of colloidal suspension. The suspension was introduced from the top, removed after a few minutes and the internal wall above was cleaned with a cotton swab. The wetted part of the internal wall was dried while slowly, rotating horizontally in order to create an

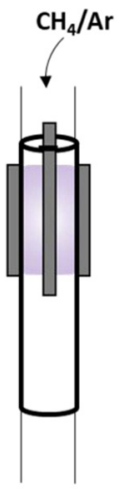

Blank reactor

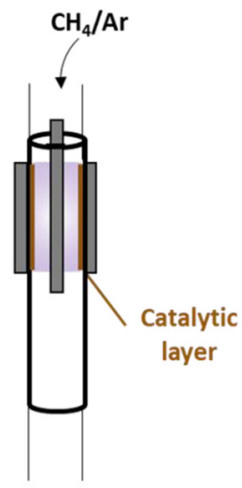

Structured reactor

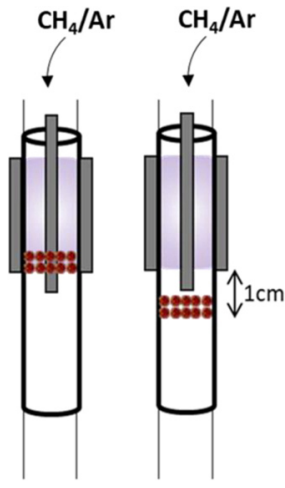

Packed bed reactors
Fig. 2. (a) DBD plasma reactors.

homogeneous layer. Impregnation and drying was repeated until the desired amount of catalyst was achieved. Then, the layer was calcined at $350{ }^{\circ} \mathrm{C}$ for $8 \mathrm{~h}$ in air with a heating rate of $2{ }^{\circ} \mathrm{C} / \mathrm{min}$ in order to slowly remove the water without creating porosity or fissures. Finally, the catalytic layer was reduced with $10 \mathrm{vol} . \% \mathrm{H}_{2}$ in $\mathrm{N}_{2}$ during $2 \mathrm{~h}$ at $350{ }^{\circ} \mathrm{C}$. The same process of drying, calcination and reduction was also performed on the remaining slurry, resulting in a powdered catalyst, which was sieved below $32 \mu \mathrm{m}$ and used for both tests in packed bed reactors as well as for characterization. Surface area and porosity was measured with $\mathrm{N}_{2}$ physisorption at $77 \mathrm{~K}$ (Micromeritics Tristar) after pretreatment in vacuum at $300^{\circ} \mathrm{C}$ for $24 \mathrm{~h}$. The Pd loading was determined by XRF (Philips PW 1480).

Three structured reactors were prepared with different loading and thickness of the catalyst layer, named according the $\mathrm{Pd} / \mathrm{\gamma}-\mathrm{Al}_{2} \mathrm{O}_{3}$ catalyst loading: Q_1.7, Q_5.9 and Q_14.8, where the numbers indicate the catalyst amount in mg (Fig. 3). The thickness and homogeneity of the catalytic layers were analysed by scanning electron microscopy (SEM) in a JEOL-LA6010 Scanning Electron Microscope.

\section{Results and discussion}

\subsection{Characterization}

The small amounts of catalyst loaded on the internal quartz walls result in apparent homogeneous thin layers, as shown in Fig. 3. As detailed characterization of thickness and homogeneity of the layers is unfortunately destructive, three reactors with similar loadings were prepared for characterization purpose only. The thickness of the catalyst layer was measured with SEM at 100-200 points at different radial and longitudinal positions, for the different catalyst loadings (Fig. 4). Fig. 5 presents the standard deviation in the multiple measurements of the thickness of the layer of the layers, indicating reasonable homogeneity of the layers, especially at low loading. Fig. 5 also shows that the thickness increases with catalyst loading, as expected, allowing estimation of the averaged thickness of the catalyst layer based on the catalyst loading. The estimated average thicknesses of the catalytic layers in Q_1.7, Q_5.9 and Q_14.8 are 4, 15 and $37 \mu \mathrm{m}$, respectively. Thus, the catalyst decreases the reactor volume and the residence time with at most $4 \%$. Therefore, it is reasonable to assume that the contact time in the plasma and consequently the SEI remains constant in all experiments.

The $\mathrm{Pd} / \mathrm{Al}_{2} \mathrm{O}_{3}$ powder catalyst, prepared with the remaining slurry and mimicking the washcoat, was characterized with $\mathrm{N}_{2}$-physisorption (Table 1). The specific surface area, the pore size as well as the pore volume remain unchanged, confirming the structure of the original catalyst is preserved. The XRF analysis resulted in a Pd loading slightly lower than the $1 \%$ loading of the parent catalyst, caused by adding 


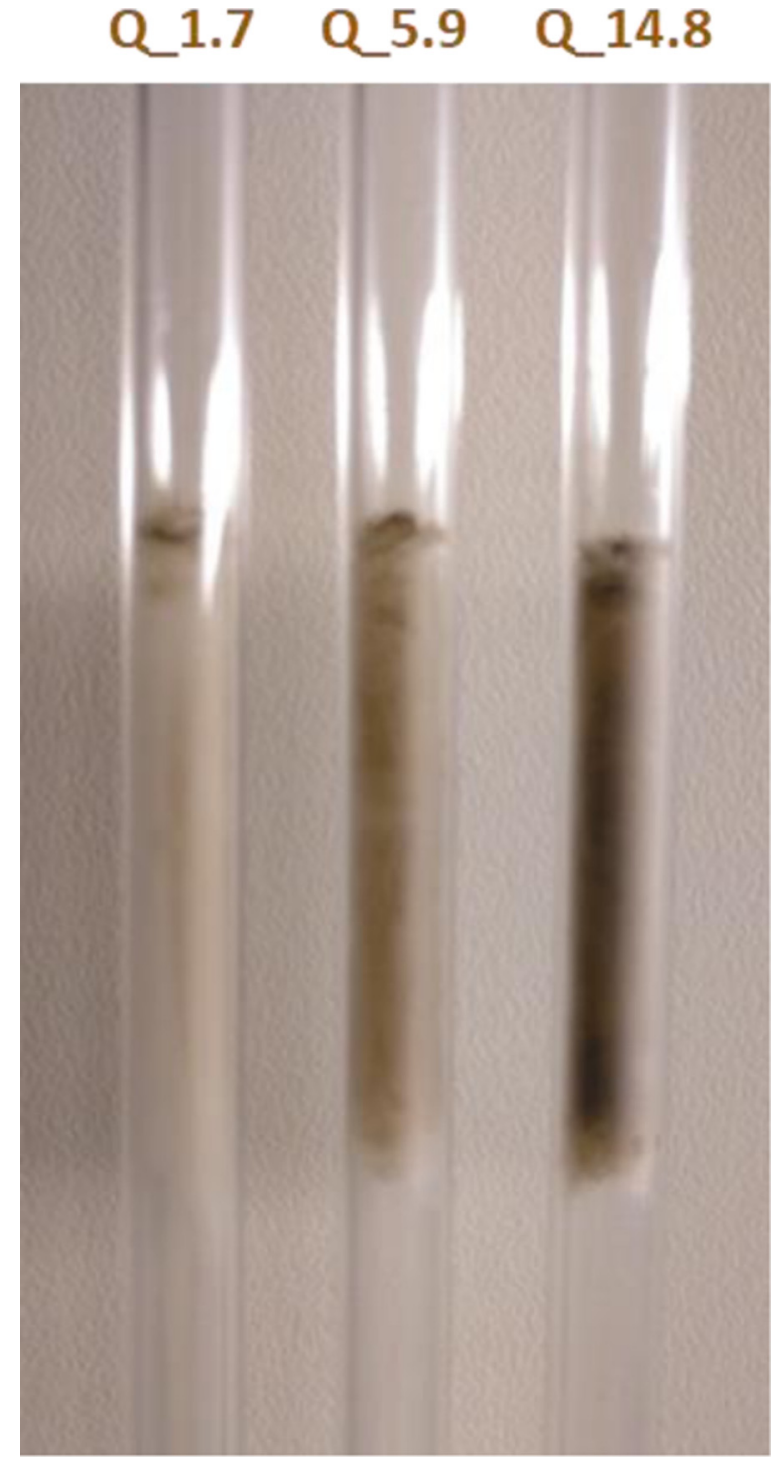

Fig. 3. Photograph of structured DBD plasma reactors with different catalyst loadings.

colloidal alumina.

\subsection{Plasma-assisted catalytic wall reactors}

Fig. 6a shows the change in discharge powers with time on stream. The applied voltages for the blank and the structured reactors were varied slightly in order to obtain the same initial power level $(\sim 2.8 \mathrm{~W})$, as indicated in the figure. Since the presence of a thin catalytic layer implies a small extra capacitance between the electrodes in addition to the quartz dielectric barrier (reactor wall), a minor adjustment in the applied voltage was necessary for that purpose. A continuous decrease of the obtained power with time on stream is observed for all reactors, by repetitively measuring Lissajous plots. Interestingly, the decrease of the discharge power with time for the structured reactors is less pronounced with increasing thickness of the catalyst layer and most pronounced for the blank reactor. The decrease in power during $180 \mathrm{~min}$ time on stream decreases in the order Blank $>$ Q_1.7 $>$ Q_5.9> Q_14.8 $(22.9 \%>18.0 \%>16.1 \%>11.1 \%$ of power loss, respectively).

Fig. $6 \mathrm{~b}$ shows that also the methane conversion decreases with timeon-stream, as a consequence of the decreasing discharge power. The decrease in power and methane conversion is likely caused by the formation of carbonaceous deposits, including conductive filaments in the reactor, decreasing the dielectric discharge through the gap [27]. Fig. $6 c$ demonstrates that addition of the catalyst layer decreases the formation of deposits significantly. Note that deposits are the main product in an empty reactor.

Fig. $6 \mathrm{~b}$ also shows that presence of the layer decreases the methane conversion. However, the thickness of the Pd catalyst layer does not influence the conversion. This suggests that only the external surface is involved, instead of the internal surface area of the catalyst layer. We assign this to hydrogenation of methyl radicals, formed in the plasma, with hydrogen chemisorbed on $\mathrm{Pd}$, back to methane $\left(\bullet \mathrm{CH}_{3}+\mathrm{H}_{a d s} \rightarrow \mathrm{CH}_{4}\right)$. As methyl radicals are short lived, diffusion is possible only over a distance in the order of microns, explaining that exclusively the outer surface area of the layers can contribute $[34,51]$. In any case, the plasma power mainly controls the conversion of methane, although the catalyst decreases the conversion slightly via hydrogenation of methyl radicals at the external surface of the catalyst layer.

In contrast, the product distribution and formation of deposits is influenced by the thickness of the Pd catalyst layer as shown in Figs. 6c and 7 , indicating that the internal surface area is contributing. Addition of the thinnest catalyst layer causes a decrease in the formation of acetylene, 1,3-butadiene and mainly carbonaceous deposits, in benefit of ethylene, propylene, saturated hydrocarbons as well as hydrogen. Higher catalyst loading cause a decrease in the selectivity to unsaturated hydrocarbons as well as to deposits, decreasing for instance the formation of acetylene, which is reported to be a precursor for coke formation [10,52]. The main increase is observed for ethane. In short, hydrogenation reactions proceed also on the internal surface of the catalyst layers. Formation of deposits decreases concurrently, suggesting that hydrogenation of acetylene contributes to suppressing of formation of deposits by preventing acetylene oligomerization.

Fig. 8 shows conversion and selectivities, grouped in compounds with the same carbon-numbers $\mathrm{C}_{2}\left(\mathrm{C}_{2} \mathrm{H}_{2}, \mathrm{C}_{2} \mathrm{H}_{4}, \mathrm{C}_{2} \mathrm{H}_{6}\right), \mathrm{C}_{3}\left(\mathrm{C}_{3} \mathrm{H}_{6}, \mathrm{C}_{3} \mathrm{H}_{8}\right)$ and $\mathrm{C}_{4}\left(1,3-\mathrm{C}_{4} \mathrm{H}_{6}, 1-\mathrm{C}_{4} \mathrm{H}_{8}, \mathrm{n}-\mathrm{C}_{4} \mathrm{H}_{10}\right.$, iso- $\left.\mathrm{C}_{4} \mathrm{H}_{10}\right)$, as well as the selectivity to carbon deposits, identical to the data in Fig. 7b. The product distribution hardly changes with time-on-stream despite the observed deactivation and power decrease, since the selectivity patterns are very similar after $20 \mathrm{~min}$ and $180 \mathrm{~min}$ of reaction in Fig. $8 \mathrm{a}$ and b. This confirms that activation of methane depends mainly on the plasma and carbon formation is affecting the power discharge, decreasing the conversion with time-on-stream. Interestingly, the hydrogenation activity of the Pd catalyst is not deactivated by carbon deposition, achieving the same suppression of carbon formation independent of time-on-stream, amount of deposits formed and plasma power.

During the experiments, a yellowish polymeric deposit is formed on the quartz wall whereas the stainless-steel electrode is covered with a black deposit. Table 2 presents the amounts observed after each experiment during $180 \mathrm{~min}$, as determined by weighing. The carbon selectivity is calculated according Eq. (5). The black solid formed on the central electrode surface is considered as carbon, whereas the $\mathrm{C}$ content of the deposit formed on the quartz internal surface was calculated based on the $\mathrm{CHN}$ elemental analysis, resulting in a $\mathrm{C} / \mathrm{H}$ molar ratio of $1 / 1.7$.

The relatively poor carbon balance calculated with Eq. (6) for the blank reactor (Table 2) implies that about $20 \%$ of the products could not be detected with GC, whereas the mass balances for the catalytic wall reactors close much better, independent of the thickness of the catalyst layer. In contrast, the amount of deposits formed decreases significantly with increasing amount of catalyst, especially on the quartz wall. The trends reported in Table 2 are very similar to those observed in Figs. 6-8. As an example, the amount of carbon formed decreases with a factor 4 when comparing the blank reactor with the Q_14.8 reactor based on weighing (Table 2), and with a factor 3 based on integration over time-on-stream of the GC analyses used for construction of Fig. 6c. However, the absolute numbers on selectivity to 

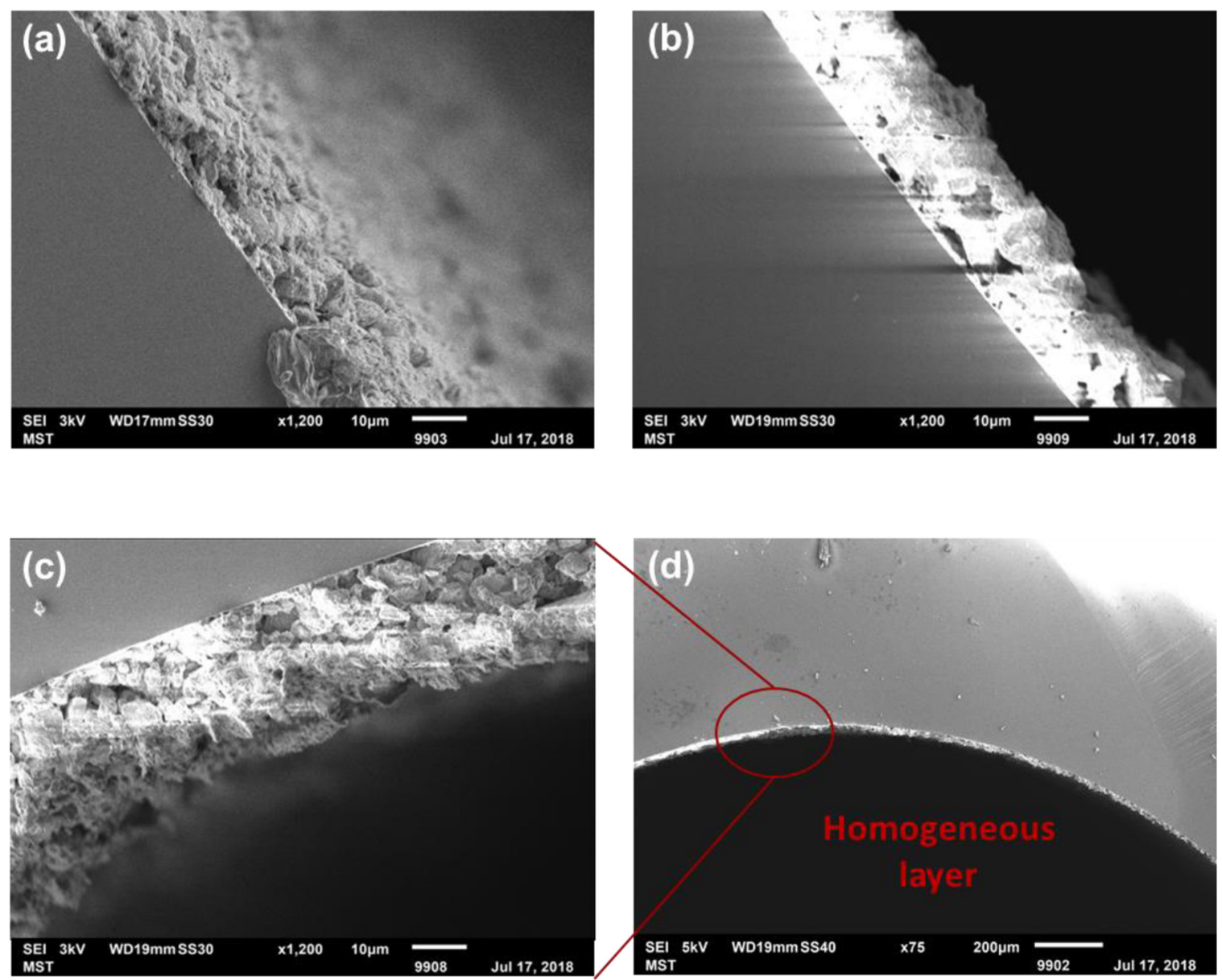

Fig. 4. SEM images of the catalytic layers loaded on internal quartz wall: (a) analogous to Q_1.7 loading, (b) analogous to Q_5.9 loading, (c) analogous to Q_14.8 loading and (d) zoom out of image (c).

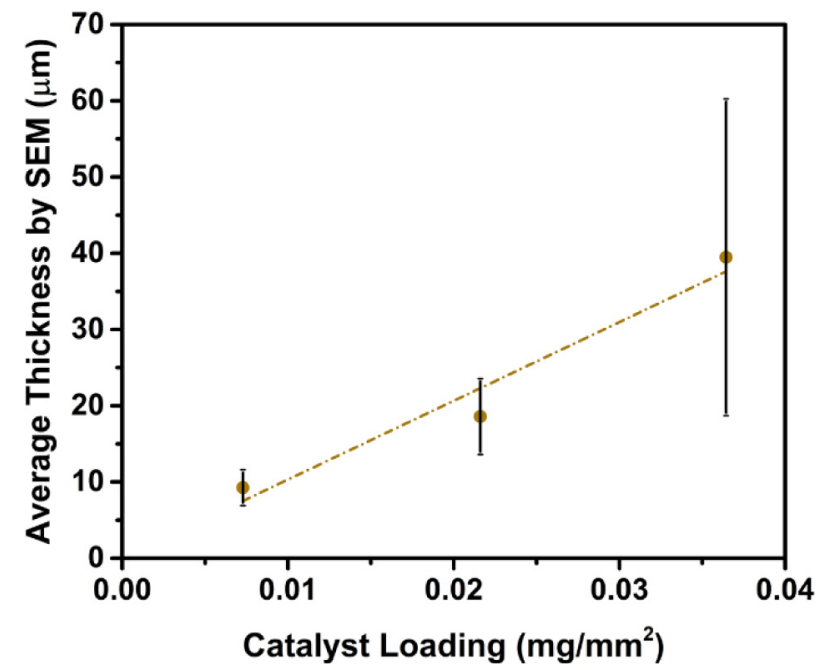

Fig. 5. Influence of catalyst loading on the thicknesses of the catalyst layer measured with SEM at multiple positions in the catalytic wall; the bars indicate the standard deviation, the number of observations varies between 100 and 200.

deposits reported in Table 2 and those plotted in Figs. 6-8, assuming all missing $\mathrm{C}$ ends up as deposit, are quite different. This is due to inaccuracies. Measurement of the integral amount of deposits as well as the elemental composition for the data in Table 2 is rather precise, but the calculated value is an average in time. This may introduce
Table 1

Textural properties of the original $\mathrm{Pd} / \mathrm{Al}_{2} \mathrm{O}_{3}$ catalyst and powder catalyst minicking the washcoat.

\begin{tabular}{llll}
\hline Sample & $\mathrm{S}_{\mathrm{BET}}\left(\mathrm{m}^{2} / \mathrm{g}\right)$ & $\mathrm{D}_{\text {pore }}(\mathrm{nm})$ & $\mathrm{V}_{\text {pore }}\left(\mathrm{cm}^{3} / \mathrm{g}\right)$ \\
\hline Original $\mathrm{Pd} / \mathrm{Al}_{2} \mathrm{O}_{3}$ & 159 & 10.1 & 0.47 \\
Powder & 169 & 10.0 & 0.48 \\
\hline
\end{tabular}

significant error because of the observed deactivation. On the other hand, the data presented in Figs. 6-8 contain errors because part of the missing carbon in the mass balance is caused by undetected hydrocarbons and deposits in gas lines outside the reactor, especially in the blank reactor.

Hence, high methane conversions are achieved in our work and the thickness of the catalytic layer has no significant influence on the conversion level, indicating that both plasma properties as well as the reaction conditions are preserved. Thus, the suppression of formation of deposits is attributed to a catalytic effect via enhancing hydrogenation reactions. In particular, $70 \%$ selectivity to value-added hydrocarbons $\left(\mathrm{C}_{2}-\mathrm{C}_{4}\right)$ is achieved at constant methane conversion level (c.a. $\left.34 \%\right)$ when operating with $14.8 \mathrm{mg}$ of catalyst $\left(81.3 \mathrm{Lh}^{-1} \mathrm{~g}^{-1}\right)$ at room temperature, obtaining a carbon balance of $93 \%$, as a result of decreasing the deposit formation with more than a factor of 2 . Hence, this structured configuration improves the performance compared to an empty plasma reactor, somewhat similar to the results of Bao et al. in thermal operation. In that work, the blank reactor converted only $2.5 \%$ of methane with $95 \%$ selectivity to coke, whereas optimized catalytic reactor with $0.5 \% \mathrm{FeCSiO}_{2}\left(21.4 \mathrm{~L} \mathrm{~h}^{-1} \mathrm{~g}^{-1}\right)$ converts $48 \%$ of methane 
(a)

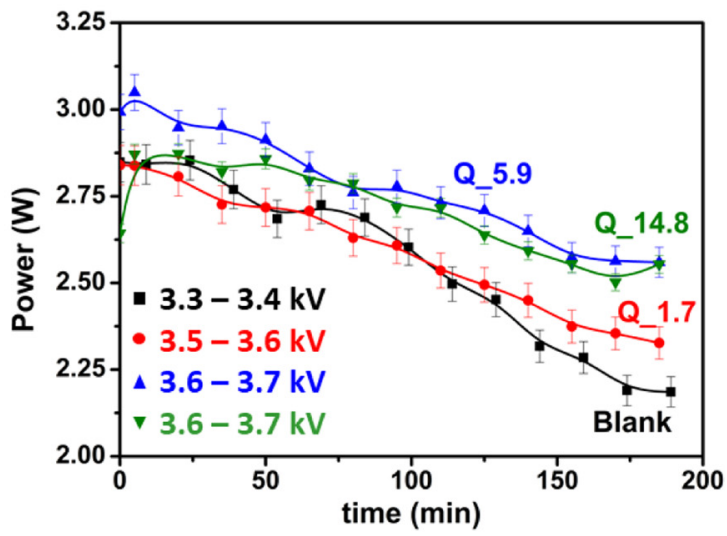

(b)

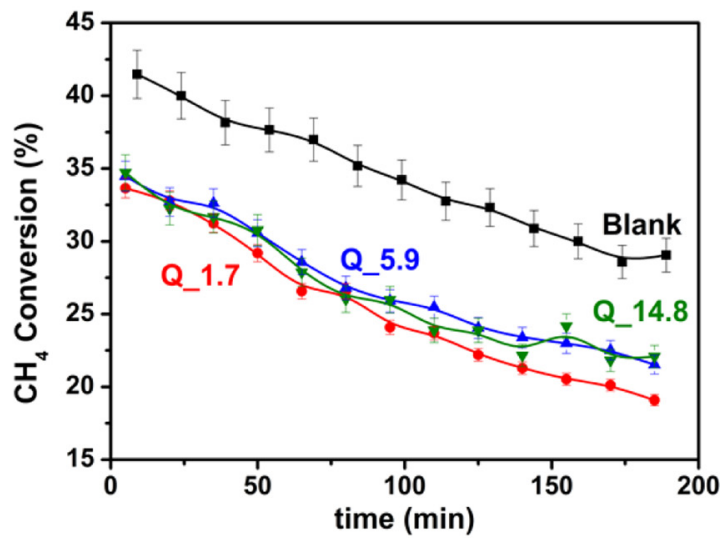

(c)

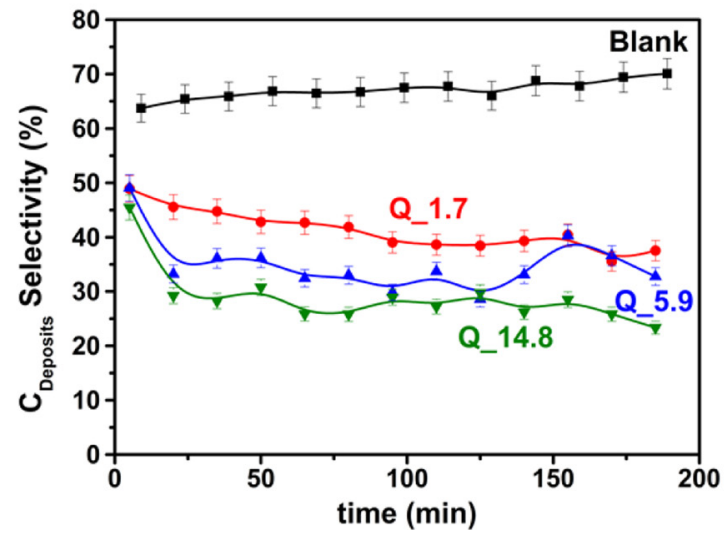

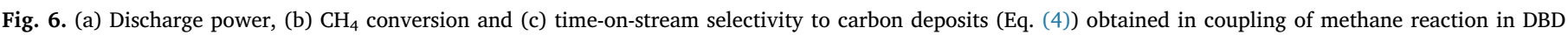
plasma reactors (blank reactor and catalytic structured reactors) during $3 \mathrm{~h}$.

(a)

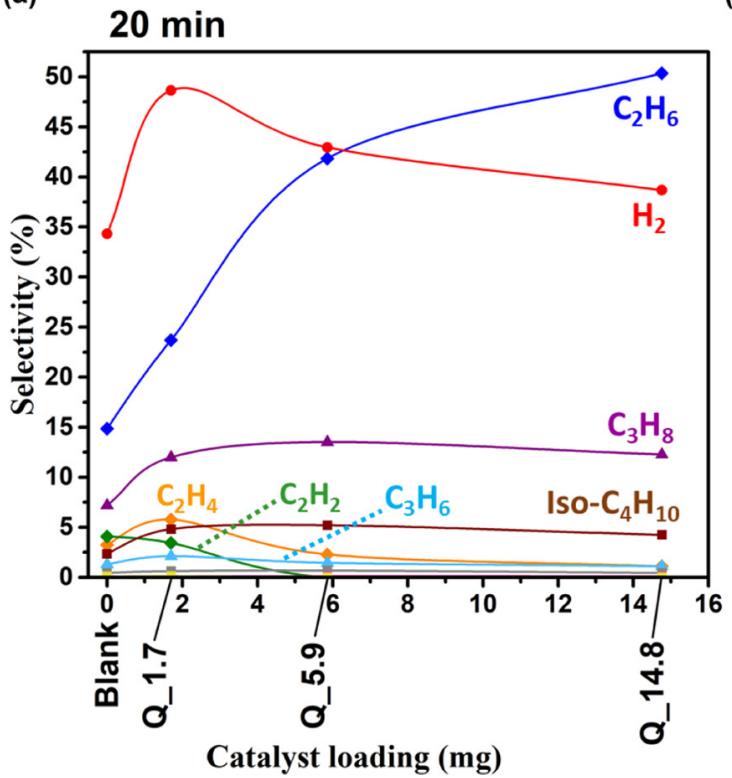

(b)

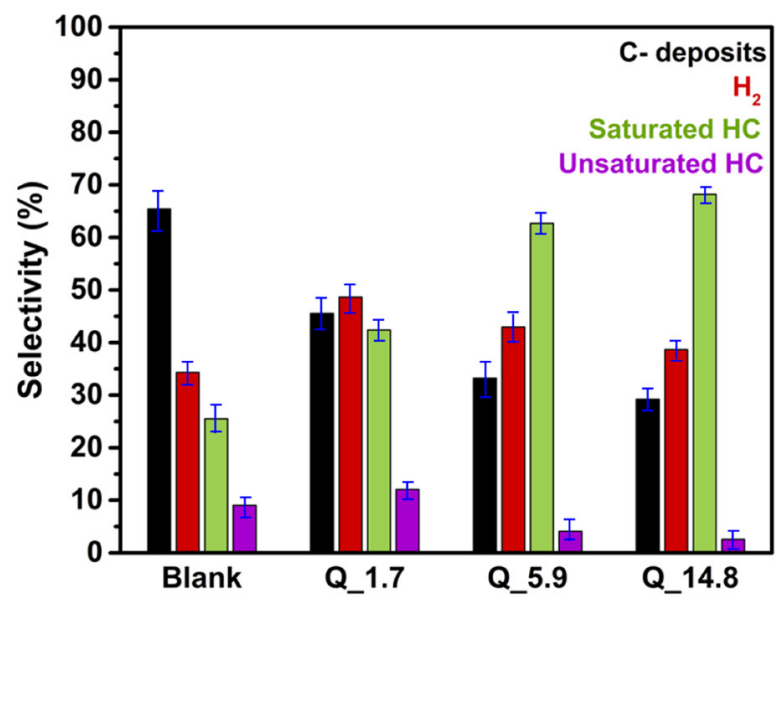

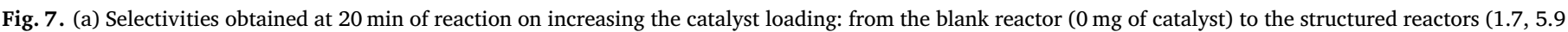

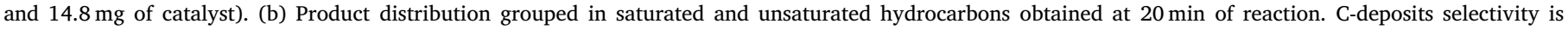
estimated including all the missed C-species (Eq. (4)). 
(a)

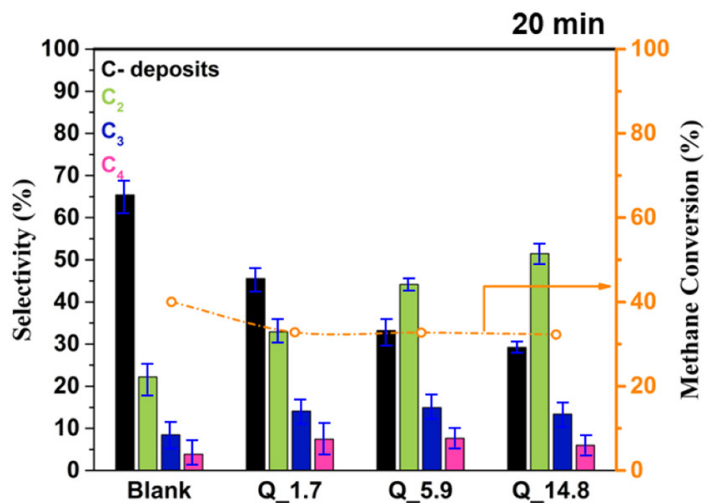

(b)

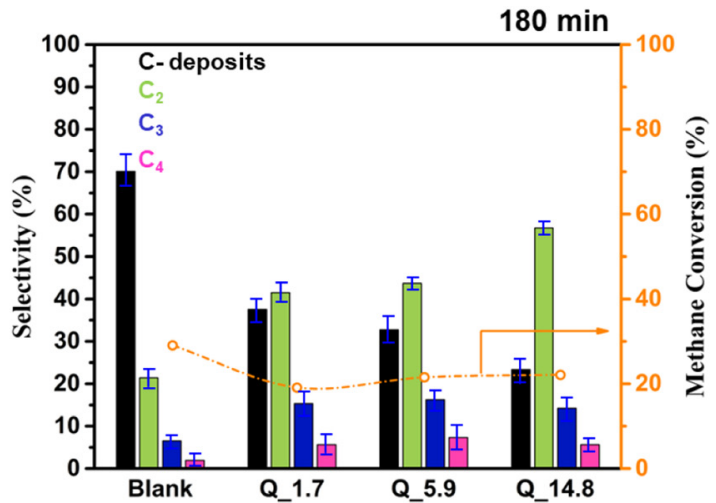

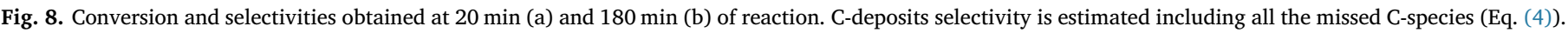

Table 2

Weight of deposits formed in $3 \mathrm{~h}$, carbon and hydrogen balances, and selectivity of solid deposits.

\begin{tabular}{llllll}
\hline Experiment & $\begin{array}{l}\text { Deposits on } \\
\text { Quartz }(\mathrm{mg})\end{array}$ & $\begin{array}{l}\text { Deposits on } \\
\text { Electrode }(\mathrm{mg})\end{array}$ & $\mathrm{C}_{\text {bal }}$ & $\mathrm{H}_{\text {bal }}$ & Selectivity $^{\mathrm{a}}(\%)$ \\
\hline Blank & 6.6 & 1.0 & 0.82 & 0.86 & 17.4 \\
Q_1.7 & 5.8 & 0.8 & 0.95 & 0.99 & 20.8 \\
Q_5.9 & 3.5 & 0.7 & 0.94 & 0.98 & 12.6 \\
Q_14.8 & 1.0 & 0.5 & 0.93 & 0.97 & 4.7 \\
\hline
\end{tabular}

a Selectivity calculated based on weights of deposits and CHN analysis, using Eq. (5).

with less than $1 \%$ selectivity to deposits at $1363 \mathrm{~K}$ [5]. On the other hand, there are only a few studies on methane coupling with DBD plasma in similar reaction conditions. Jo et al. [19] achieved methane conversion of c.a. $13 \%$ using a discharge power resulting in a SEI of $603 \mathrm{~kJ} / \mathrm{mol} \mathrm{CH}_{4}$ with a poor carbon balance of only $70 \%$, due to the formation of carbonaceous deposits. The carbon balance could only be improved by adding oxygen in the feed, at the expense of poor selectivity to hydrocarbons due to oxidation to $\mathrm{CO}$ and $\mathrm{CO}_{2}$. Recently, Zhang et al. [20] used pulsed DBD plasma for non-oxidative coupling of methane obtaining conversions below $10 \%$ and selectivity to hydrocarbons $\left(\mathrm{C}_{2}-\mathrm{C}_{4}\right)$ below $50 \%$. Saleem and co-workers [14] obtained 37 $\%$ methane conversion with a SEI of $3665 \mathrm{~kJ} / \mathrm{mol} \mathrm{CH}_{4}$ with rather poor $\mathrm{C}$ balances of typically $70 \%$. Unfortunately, a detailed comparison with these results is not possible because conversion and selectivities depend on the SEI, DBD reactor dimensions and reaction conditions $[10,25,26]$, which differ significantly in all studies. Nevertheless, all studies agree on the point that formation of deposits is a key problem; our work quantifies the amount of deposits rigorously and shows that addition of a hydrogenation catalyst results in significant improvement.

Several reaction schemes for plasma activated methane coupling have been proposed $[23,54,55]$. Our work shows that a hydrogenation catalyst enhances hydrogenation reactions, including hydrogenation of methyl radicals as well as of molecular acetylenes. Further interpretation in terms of the reaction schemes is unfortunately not possible.

It should also be noted that the results obtained in this study, as well as in all previous reports discussed above, cannot yet serve as a basis for development of practical technology because of very low energy efficiency. This follows directly from the high SEI numbers varying in the order of $3000 \mathrm{~kJ} / \mathrm{mol}$ methane, which is much higher than the $\Delta \mathrm{H}$ of the main reactions, i.e. $2 \mathrm{CH}_{4} \rightarrow \mathrm{C}_{2} \mathrm{H}_{6}+\mathrm{H}_{2}(+66 \mathrm{~kJ} / \mathrm{mol})$ and $2 \mathrm{CH}_{4} \rightarrow$ $\mathrm{C}_{2} \mathrm{H}_{4}+2 \mathrm{H}_{2}(+202 \mathrm{~kJ} / \mathrm{mol})$. The energy efficiency, defined as the fraction of the electrical energy provided that is stored in chemical energy, is very low in the order of $1 \%$.

\subsection{Comparing to fixed bed reactors}

Analogous to experiments with the structured reactor Q_5.9, packed bed experiments were carried out with the same amount of catalyst (5.9 $\mathrm{mg}, 204.8 \mathrm{~L} \mathrm{~h}^{-1} \mathrm{~g}^{-1}$ ), using the same plasma reaction conditions $\left(2.8 \mathrm{~W}, 23 \mathrm{kHz}, \mathrm{SEI}=3423 \mathrm{~kJ} / \mathrm{mol}_{\mathrm{CH} 4}, 20 \mathrm{ml} / \mathrm{min}, 6 \% \mathrm{CH}_{4}\right.$ in $\mathrm{Ar}, 1 \mathrm{~s}$ of residence time, ambient temperature and pressure). In order to study the effect of the position of the catalyst respect to the plasma, the packed bed was positioned either inside the plasma zone or $1 \mathrm{~cm}$ downstream from the plasma. Due to the small amount of catalyst, the packed bed was rather thin, about $2 \mathrm{~mm}$. Thus, the influence of the catalyst on the plasma is again minimized, allowing comparison with the structured and blank reactors without major changes in the plasma (Fig. 9).

The power discharge in the packed bed reactors suffers a similar deactivation in time as observed previously for the blank and structured reactors (Fig. 10a). Again, the blank reactor deactivates the most and the Q_5.9 structured reactor the least. The decrease in power shown by the packed bed reactors are in between these two extremes. Similarly to structured reactors, a minor variation in methane conversion (Fig. 10b) is observed for the same power discharge, due to reverse reaction of

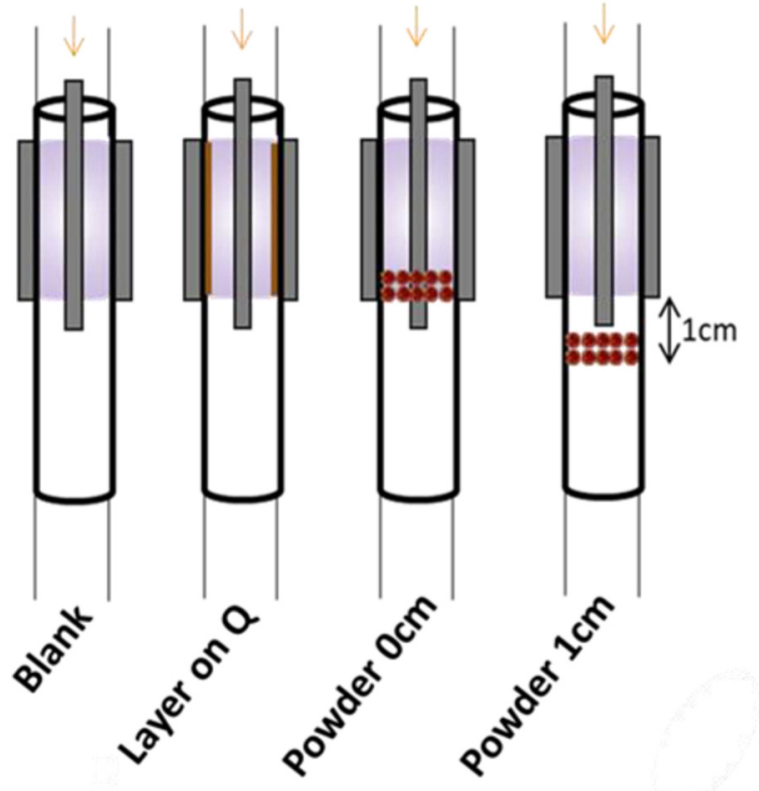

Fig. 9. DBD plasma reactors: blank, structured Q_5.9 and two packed bed reactors with $5.9 \mathrm{mg}$ of catalyst (inside the plasma and $1 \mathrm{~cm}$ downstream). 
(a)

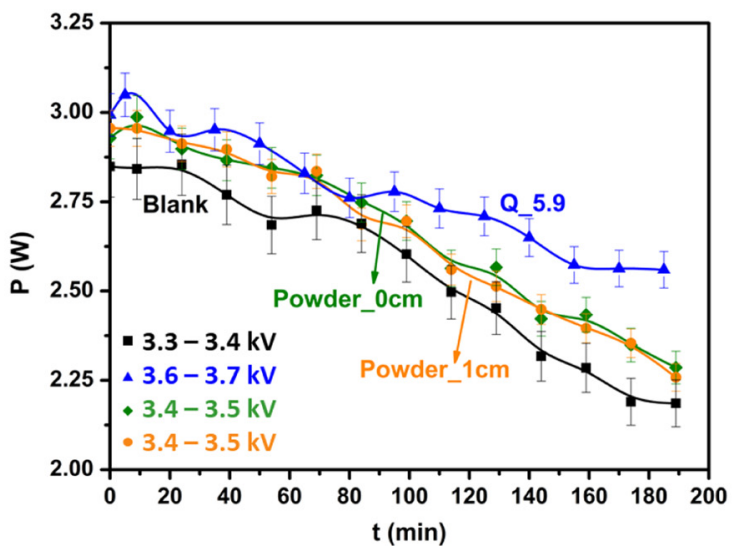

(b)

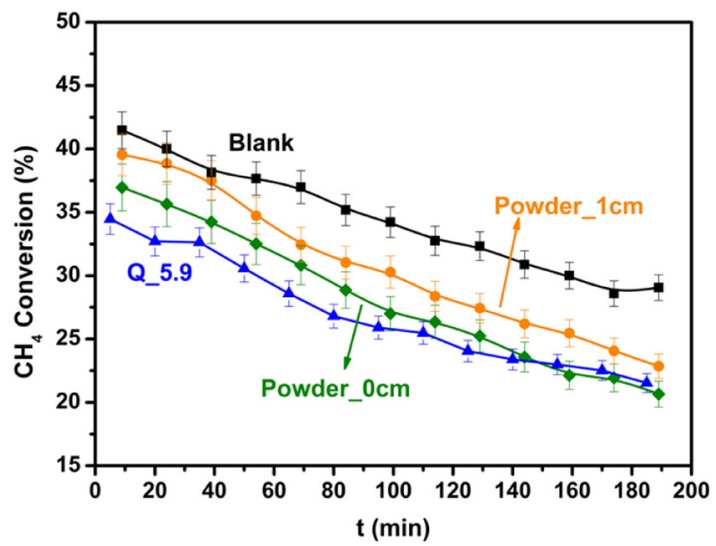

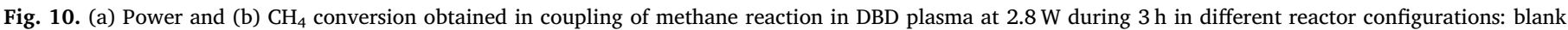

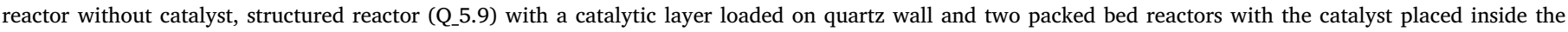
plasma $(0 \mathrm{~cm})$ or downstream $(1 \mathrm{~cm}$ from the plasma).

Structured reactor

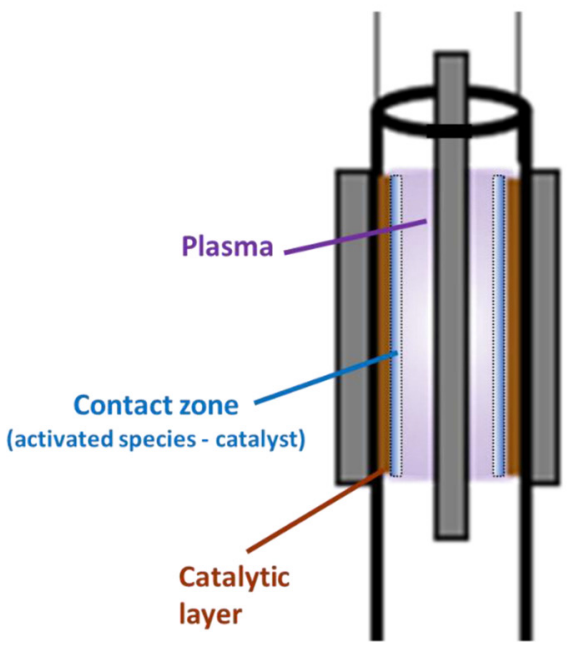

Packed bed reactor

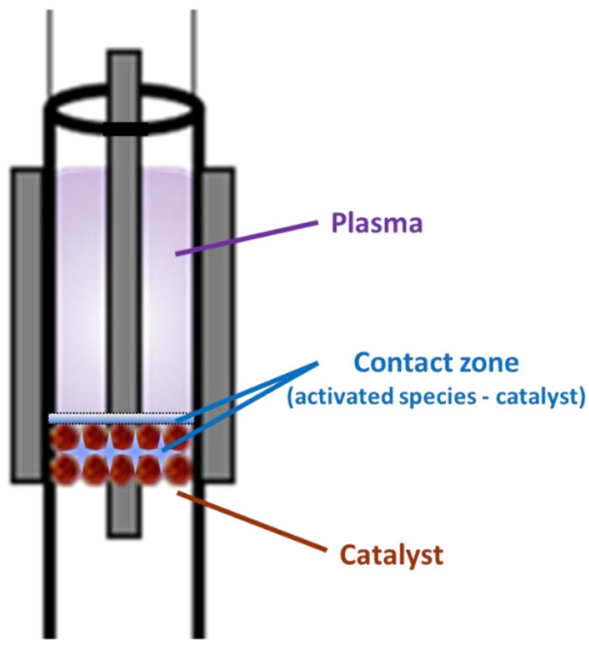

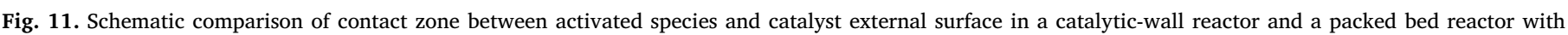
catalyst inside plasma zone.

methyl radicals to methane in presence of the catalyst. This effect of hydrogenation of methyl radicals increases in the order Powder_1 cm $<$ Powder_0 cm < Q_5.9, as conversion decreases in the same order (Fig. 10b). The fact that the catalyst is able to decrease conversion even when positioned $1 \mathrm{~cm}$ below the plasma zone is actually surprising and it demonstrates that at least part of the methyl radicals reach the catalyst bed outside the plasma zone without being quenched. As discussed above, hydrogenation of methyl radicals takes place at the surface of the catalyst. Therefore, it is logical that the catalytic wall reactor has the largest effect because the catalyst is better distributed in the plasma reactor compared to a fixed bed reactor, as schematically presented in Fig. 11. In the catalytic wall reactor, the contact between plasma and the external surface of the catalyst layer or bed is maximized.

The product distributions depicted in Figs. 12 and 13 show that also hydrogenation of unsaturated hydrocarbons to saturated hydrocarbons increases in the order Blank < Powder_1 cm < Powder_0 cm < Q_5.9. As discussed above, hydrogenation of unsaturated hydrocarbons takes place on the internal surface of the catalyst, both in a catalytic wall reactor as in a fixed bed. The catalytic bed placed inside the plasma enhances catalytic hydrogenation stronger than the catalyst positioned downstream, but still a minor effect is observed producing more saturated hydrocarbons compared to the blank reactor. Thus, hydrogenation of acetylene also increases in the same order: Blank < Powder_1 cm < Powder_0 cm < Q_5.9.

Similar results were obtained by Jo et al. [29], comparing $\mathrm{Pt} / \mathrm{Al}_{2} \mathrm{O}_{3}$ and $\mathrm{Al}_{2} \mathrm{O}_{3}$-only in a packed bed DBD reactor. However, they attributed the lower methane conversion with $\mathrm{Pt} / \mathrm{Al}_{2} \mathrm{O}_{3}$ exclusively to differences in the electric field by the presence Pt nanoparticles, changing the chemistry in the plasma. Although we cannot discard a similar contribution induced by Pd nanoparticles, we conclude that the main effect is catalytic because of three observations. First, methane conversion and product distribution are modified and the effect is qualitatively independent of the distribution and position of the catalyst in the reactor, even when the catalyst is positioned downstream of the plasma, where any effect on the electrical field can be discarded. Second, Pd present inside the catalyst layer is influencing the product distribution, whereas it is clear that formation of plasma is impossible in pores of typically $10 \mathrm{~nm}$ (Table 1 ). Third, the change in the product distribution is typical for the hydrogenation activity of a Pd or Pt catalyst.

The amount of solid deposits was also measured by weighing of the reactors before and after the experiment. Table 3 reports the amount of carbon deposited on the HV electrode and, in these cases, the sum of the 

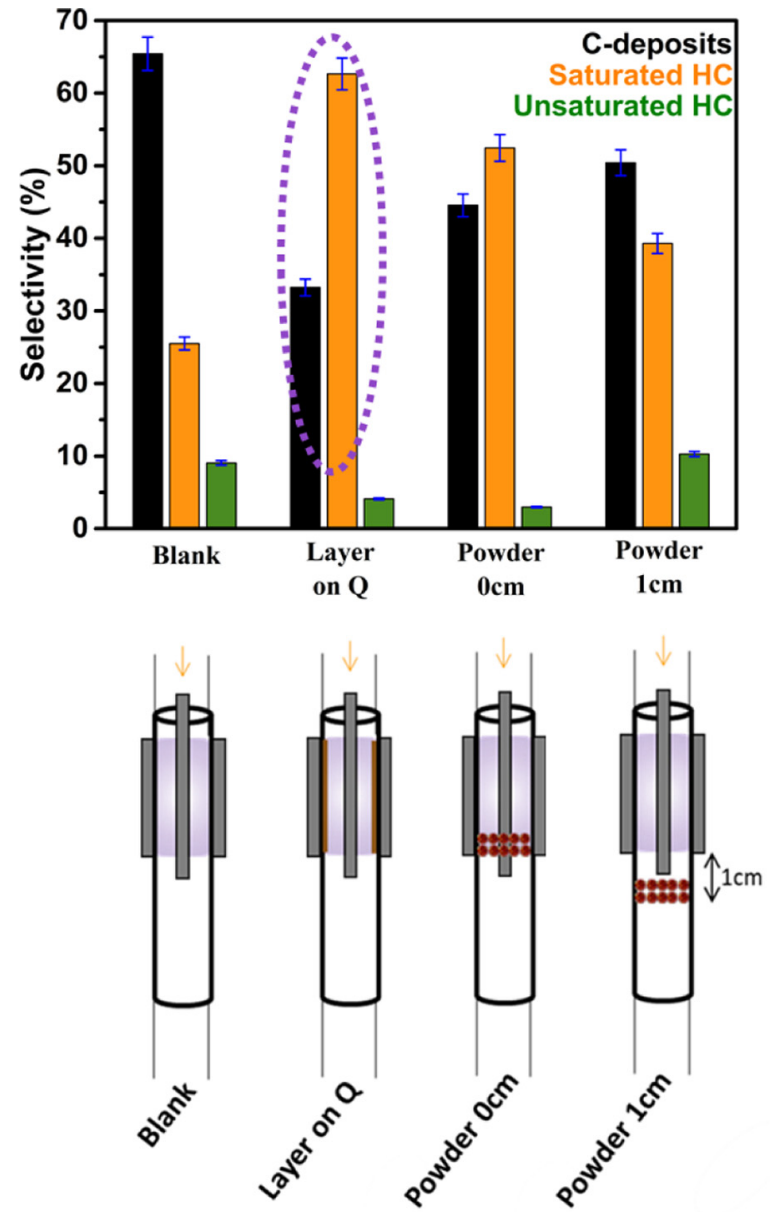

Fig. 12. Product distribution grouped in saturated and unsaturated hydrocarbons obtained after $20 \mathrm{~min}$ of reaction for different configuration at same operation conditions with $5.9 \mathrm{mg}$ of catalyst and compared to the blank reactor. C-deposits selectivity is estimated based on analysis of all C-containing species in the product mixture (Eq. (4)).

amount deposited on the internal quartz wall and on the catalytic particles. The carbon and hydrogen balances were calculated using the same method as used for discussion of the data in Table 2. The results

(a)

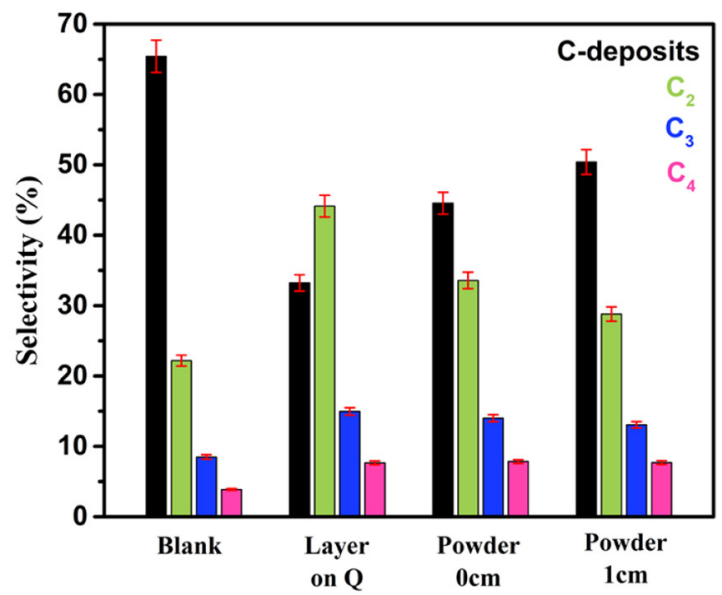

Table 3

Weight of deposits formed in $3 \mathrm{~h}$, carbon and hydrogen balances, and selectivity of solid deposits.

\begin{tabular}{llllll} 
Experiment & $\begin{array}{l}\text { Deposits on } \\
\text { Q + Cat (mg) }\end{array}$ & $\begin{array}{l}\text { Deposits on } \\
\text { Electrode (mg) }\end{array}$ & $\mathrm{C}_{\text {bal }}$ & $\mathrm{H}_{\text {bal }}$ & Selectivity $^{\text {a }}$ (\%) \\
Blank & 6.6 & 1.0 & 0.82 & 0.86 & 17.4 \\
Layer on Q_5.9 & 3.5 & 0.7 & 0.94 & 0.98 & 12.6 \\
Powder 0cm & 9.9 & 0.7 & 0.96 & 0.99 & 29.5 \\
Powder 1cm & 9.5 & 1.0 & 0.93 & 0.98 & 26.9 \\
\hline
\end{tabular}

a Selectivity calculated from weights and CHN analysis, using Eq. (5).

are quite similar to the results with catalytic wall reactors: carbon balances close remarkably well. The trends in the amount of deposits formed are quite different though: formation of deposits on catalytic wall reactors is clearly suppressed as discussed above, whereas the amount of deposits in fixed bed reactors significantly increase.

The carbon selectivity after a specific time-on-stream (Figs. 12 and 13a) is calculated assuming that the missing carbon is due to exclusively formation of deposits. However, the poor C-balance in the blank reactor (Table 3) indicates that the selectivity to deposits in the empty reactor (Fig. 13) is overestimated, caused by formation of hydrocarbons with relatively high molecular weight. Some unsaturated $\mathrm{C}_{4}$ compounds are not separated in the GC and in addition higher hydrocarbons are not detected. The fixed bed catalyst traps and possibly oligomerizes these heavier hydrocarbons, closing the carbon balance remarkably well. The hydrogenation capacity is available only in the bottom part of the plasma (Fig. 11) so that acetylene can oligomerize in the plasma zone without catalyst, and the fixed bed catalyst then traps the resulting oligomers. Hydrogenation of acetylene is possible exclusively in the small catalytic zone in the bottom of the reactor and, consequently, the suppression of deposit formation is a minor effect. Summarizing, in case of the catalytic wall reactor, suppression of formation of higher hydrocarbons and deposits via hydrogenation of acetylene dominates. This is not the case for the catalytic bed reactors because Pd is available in only a small part of the reactor and, consequently, trapping of resulting higher hydrocarbons dominates.

The limited hydrogenation capacity of the fixed bed, compared to the catalytic wall reactor, is also observed in the product distribution depicted in Fig. 13b. The catalytic bed placed inside the plasma enhances catalytic hydrogenation stronger than the catalyst positioned downstream, producing more saturated hydrocarbons. In particular, the bed in the plasma $(0 \mathrm{~cm})$ produces more ethane, less ethylene and no

(b)

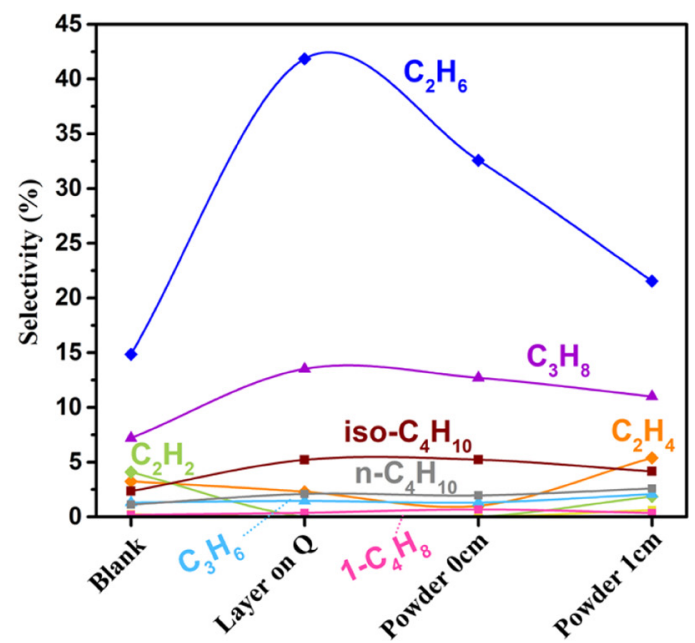

Fig. 13. Selectivities of products grouped by C-number (a) and the main products separately (b) obtained after 20 min of reaction. C-deposits selectivity is estimated based on analysis of all C-containing species in the product mixture (Eq. (4)). 
acetylene compared to the catalyst bed positioned downstream $(1 \mathrm{~cm})$. Moreover, the catalyst bed downstream the plasma zone enhances production of ethane, propane and ethylene and decreases acetylene formation compared to the blank reactor. The observations support the hypothesis that formation of deposits is suppressed by hydrogenation of acetylene, in good agreement with the general consensus that acetylene is main precursor of carbon formation [10,21,22,36,53-55].

\section{Conclusions}

DBD plasma reactors with a catalytic wall with varying thickness have been prepared via repetitive washcoating. These reactors enable studying the effect of the thickness of the catalyst layer, including the blank plasma reactor, without significant modification of plasma properties, SEI and residence time. Thus, this configuration allows analysis of the catalytic effect of the $\mathrm{Pd} / \mathrm{Al}_{2} \mathrm{O}_{3}$ catalyst. Particularly, hydrogenation reactions taking place on the Pd surface strongly influenced the product distribution, while decreasing the methane conversion only mildly. The small effect on conversion is assigned to hydrogenation of $\mathrm{CH}_{\mathrm{x}}$ radicals with chemisorbed hydrogen, at the outer surface of the catalyst layer. The formation of undesired deposits is decreased by a factor of 2 , which is assigned to hydrogenation of acetylenes on Pd at both the external and internal surface area in the catalyst layer. The best selectivity to value-added hydrocarbons $\left(\mathrm{C}_{2}-\mathrm{C}_{4}\right)$ is $70 \%$ with a methane conversion of $34 \%$. The catalytic wall reactor performs significantly better than a reactor containing the same amount of catalyst in a fixed bed. The hydrogenation activity needs to be distributed throughout the plasma zone to attain the maximal suppression of formation of deposits. The synergistic effect is much more evident when the catalyst was placed inside the plasma zone, although some interaction between radicals and the catalyst was observed with the catalyst bed positioned $1 \mathrm{~cm}$ downstream from the plasma.

\section{CRediT authorship contribution statement}

Nuria García-Moncada: Conceptualization, Data curation, Formal analysis, Investigation, Methodology, Resources, Writing - original draft, Writing - review \& editing. Gerard van Rooij: Funding acquisition, Methodology, Supervision, Writing - review \& editing. Toine Cents: Funding acquisition, Investigation, Methodology, Validation, Writing - review \& editing. Leon Lefferts: Conceptualization, Funding acquisition, Investigation, Methodology, Project administration, Supervision, Writing - review \& editing.

\section{Declaration of Competing Interest}

The authors declare that they have no known competing financial interests or personal relationships that could have appeared to influence the work reported in this paper.

\section{Acknowledgements}

This work was supported by the Innovation Fund for Chemistry of NWO, grant number 731.014.303, as well as by SASOL. The authors want to thank Dr. Guido Giammaria for the discussions and Bert Geerdink for the technical assistance.

\section{References}

[1] J.H. Lunsford, Catalytic conversion of methane to more useful chemicals and fuels: a challenge for the 21st century, Catal. Today 63 (2000) 165-174, https://doi.org/ 10.1016/S0920-5861(00)00456-9.

[2] P. Tang, Q. Zhu, Z. Wu, D. Ma, Methane activation: the past and future, Energy Environ. Sci. 7 (2014) 2580-2591, https://doi.org/10.1039/c4ee00604f.

[3] B. Wang, S. Albarracín-Suazo, Y. Pagán-Torres, E. Nikolla, Advances in methane conversion processes, Catal. Today 285 (2017) 147-158, https://doi.org/10.1016/ j.cattod.2017.01.023.
[4] C. Mesters, A selection of recent advances in C1 chemistry, Annu. Rev. Chem. Biomol. Eng. 7 (2016) 223-238, https://doi.org/10.1146/annurev-chembioeng080615-034616.

[5] X. Guo, G. Fang, G. Li, H. Ma, H. Fan, L. Yu, C. Ma, X. Wu, D. Deng, M. Wei, D. Tan, R. Si, S. Zhang, J. Li, L. Sun, Z. Tang, X. Pan, X. Bao, Direct, nonoxidative conversion of methane to ethylene, aromatics and hydrogen, Science (80-.) 344 (2014) 616-619, https://doi.org/10.1126/science.1248783.

[6] M. Sakbodin, Y. Wu, S.C. Oh, E.D. Wachsman, D. Liu, Hydrogen-permeable tubular membrane reactor: promoting conversion and product selectivity for non-oxidative activation of methane over an Fe(CSiO2Catalyst, Angew. Chemie - Int. Ed. 55 (2016) 16149-16152, https://doi.org/10.1002/anie.201609991.

[7] Y. Chen, X. Wang, X. Luo, X. Lin, Y. Zhang, Non-oxidative methane conversion using lead- and iron-modified albite catalysts in fixed-bed reactor, Chinese J. Chem. 36 (2018) 531-537, https://doi.org/10.1002/cjoc.201700800.

[8] Y. Xiao, A. Varma, Highly selective nonoxidative coupling of methane over Pt-Bi bimetallic catalysts, ACS Catal. 8 (2018) 2735-2740, https://doi.org/10.1021/ acscatal.8b00156.

[9] P. Xie, T. Pu, A. Nie, S. Hwang, S.C. Purdy, W. Yu, D. Su, J.T. Miller, C. Wang, Nanoceria-supported single-atom platinum catalysts for direct methane conversion, ACS Catal. 8 (2018) 4044-4048, https://doi.org/10.1021/acscatal.8b00004.

[10] M. Scapinello, E. Delikonstantis, G.D. Stefanidis, The panorama of plasma-assisted non-oxidative methane reforming, Chem. Eng. Process. Process Intensif. 117 (2017) 120-140, https://doi.org/10.1016/j.cep.2017.03.024.

[11] P.J. Bruggeman, F. Iza, R. Brandenburg, Foundations of atmospheric pressure nonequilibrium plasmas, Plasma Sources Sci. Technol. 26 (2017) 1-17, https://doi.org/ 10.1088/1361-6595/aa97af 123002.

[12] S. Kado, Y. Sekine, T. Nozaki, K. Okazaki, Diagnosis of atmospheric pressure low temperature plasma and application to high efficient methane conversion, Catal. Today 89 (2004) 47-55, https://doi.org/10.1016/j.cattod.2003.11.036.

[13] A. Majumdar, J.F. Behnke, R. Hippler, K. Matyash, R. Schneider, Chemical reaction studies in CH4/Ar and CH4/N2 gas mixtures of a dielectric barrier discharge, J. Phys. Chem. A 109 (2005) 9371-9377, https://doi.org/10.1021/jp053588a.

[14] F. Saleem, J. Kennedy, U.H. Dahiru, K. Zhang, A. Harvey, Methane conversion to H2 and higher hydrocarbons using Non-thermal plasma dielectric barrier discharge reactor, Chem. Eng. Process. - Process Intensif. (2019) 107557., https://doi.org/10. 1016/j.cep.2019.107557.

[15] S.K. Kundu, E.M. Kennedy, V.V. Gaikwad, T.S. Molloy, B.Z. Dlugogorski, Experimental investigation of alumina and quartz as dielectrics for a cylindrical double dielectric barrier discharge reactor in argon diluted methane plasma, Chem. Eng. J. 180 (2012) 178-189, https://doi.org/10.1016/j.cej.2011.11.039.

[16] B. Wang, W. Yan, W. Ge, X. Duan, Methane conversion into higher hydrocarbons with dielectric barrier discharge micro-plasma reactor, J. Energy Chem. 22 (2013) 876-882, https://doi.org/10.1016/S2095-4956(14)60267-9.

[17] S. Jo, D. Hoon Lee, W. Seok Kang, Y.-H. Song, Methane activation using noble gases in a dielectric barrier discharge reactor, Phys. Plasmas 20 (2013) 083509, , https:// doi.org/10.1063/1.4818795.

[18] S. Jo, D.H. Lee, K.T. Kim, W.S. Kang, Y.-H. Song, Methane activation using Kr and Xe in a dielectric barrier discharge reactor, Phys. Plasmas 21 (2014) 103504, , https://doi.org/10.1063/1.4897171.

[19] S. Jo, D. Hoon Lee, Y.H. Song, Product analysis of methane activation using noble gases in a non-thermal plasma, Chem. Eng. Sci. 130 (2015) 101-108, https://doi. org/10.1016/j.ces.2015.03.019.

[20] S. Zhang, Y. Gao, H. Sun, H. Bai, R. Wang, T. Shao, Time-resolved characteristics and chemical kinetics of non-oxidative methane conversion in repetitively pulsed dielectric barrier discharge plasmas, J. Phys. D Appl. Phys. 51 (2018) 274005, , https://doi.org/10.1088/1361-6463/aac5ad.

[21] D.H. Lee, K.-T. Kim, Y.-H. Song, W.S. Kang, S. Jo, Mapping plasma chemistry in hydrocarbon fuel processing processes, Plasma Chem. Plasma Process. 33 (2013) 249-269, https://doi.org/10.1007/s11090-012-9407-7.

[22] A. Indarto, N. Coowanitwong, J.W. Choi, H. Lee, H.K. Song, Kinetic modeling of plasma methane conversion in a dielectric barrier discharge, Fuel Process. Technol. 89 (2008) 214-219, https://doi.org/10.1016/j.fuproc.2007.09.006.

[23] S. Kudryashov, A. Ryabov, G. Shchyogoleva, A new approach to the non-oxidative conversion of gaseous alkanes in a barrier discharge and features of the reaction mechanism, J. Phys. D Appl. Phys. 49 (2016) 025205, , https://doi.org/10.1088/ 0022-3727/49/2/025205.

[24] C. Xu, X. Tu, Plasma-assisted methane conversion in an atmospheric pressure dielectric barrier discharge reactor, J. Energy Chem. 22 (2013) 420-425, https://doi org/10.1016/S2095-4956(13)60055-8.

[25] J. Lü, Z. Li, Conversion of natural gas to C2 hydrocarbons via cold plasma technology, J. Nat. Gas Chem. 19 (2010) 375-379, https://doi.org/10.1016/S10039953(09)60082-7.

[26] S.Y. Liu, D.H. Mei, Z. Shen, X. Tu, Nonoxidative conversion of methane in a dielectric barrier discharge reactor: prediction of reaction performance based on neural network model, J. Phys. Chem. C. 118 (2014) 10686-10693, https://doi. org/10.1021/jp502557s.

[27] E. Delikonstantis, M. Scapinello, G.D. Stefanidis, Low energy cost conversion of methane to ethylene in a hybrid plasma-catalytic reactor system, Fuel Process. Technol. 176 (2018) 33-42, https://doi.org/10.1016/j.fuproc.2018.03.011.

[28] R.S. Berry, The theory of penning ionization, Radiat. Res. 59 (1974) 367-375.

[29] S. Jo, T. Kim, D.H. Lee, W.S. Kang, Y.H. Song, Effect of the electric conductivity of a catalyst on methane activation in a dielectric barrier discharge reactor, Plasma Chem. Plasma Process. 34 (2014) 175-186, https://doi.org/10.1007/s11090-0139505-1.

[30] T. Nozaki, K. Okazaki, Non-thermal plasma catalysis of methane: principles, energy efficiency, and applications, Catal. Today 211 (2013) 29-38, https://doi.org/10. 
1016/j.cattod.2013.04.002

[31] E.C. Neyts, A. Bogaerts, Understanding plasma catalysis through modelling and simulation - A review, J. Phys. D Appl. Phys. 47 (2014) 224010-224027, https:// doi.org/10.1088/0022-3727/47/22/224010.

[32] E.C. Neyts, K. Ostrikov, M.K. Sunkara, A. Bogaerts, Plasma catalysis: synergistic effects at the nanoscale, Chem. Rev. 115 (2015) 13408-13446, https://doi.org/10. 1021/acs.chemrev.5b00362.

[33] J.C. Whitehead, Plasma-catalysis: The known knowns, the known unknowns and the unknown unknowns, J. Phys. D Appl. Phys. 49 (2016) 243001, , https://doi. org/10.1088/0022-3727/49/24/243001.

[34] J.C. Whitehead, Plasma-catalysis: is it just a question of scale? Front. Chem. Sci. Eng. (2019) 1-10, https://doi.org/10.1007/s11705-019-1794-3.

[35] T. Butterworth, R. Elder, R. Allen, Effects of particle size on $\mathrm{CO} 2$ reduction and discharge characteristics in a packed bed plasma reactor, Chem. Eng. J. 293 (2016) 55-67, https://doi.org/10.1016/j.cej.2016.02.047.

[36] J. Kim, J. Jeoung, J. Jeon, J. Kim, Y.S. Mok, K.S. Ha, Effects of dielectric particles on non-oxidative coupling of methane in a dielectric barrier discharge plasma reactor, Chem. Eng. J. (2018) 1-13, https://doi.org/10.1016/j.cej.2018.09.057.

[37] Y. Uytdenhouwen, S. Van Alphen, I. Michielsen, V. Meynen, P. Cool, A. Bogaerts, A packed-bed DBD micro plasma reactor for $\mathrm{CO} 2$ dissociation: does size matter? Chem. Eng. J. 348 (2018) 557-568, https://doi.org/10.1016/j.cej.2018.04.210.

[38] Z.-I. Mujahid, A. Hala, Plasma dynamics in a packed bed dielectric barrier discharge (DBD) operated in helium, J. Phys. D Appl. Phys. 51 (2018) 1-6, https://doi.org/10. 1088/1361-6463/aaa8cd 11LT02.

[39] T. Butterworth, R.W.K. Allen, Plasma-catalyst interaction studied in a single pellet DBD reactor: dielectric constant effect on plasma dynamics, Plasma Sources Sci. Technol. 26 (2017) 65008-65023, https://doi.org/10.1088/1361-6595/aa6c35.

[40] K.M. Bal, S. Huygh, A. Bogaerts, E.C. Neyts, Effect of plasma-induced surface charging on catalytic processes: application to CO2 activation, Plasma Sources Sci. Technol. 27 (2018) 024001, , https://doi.org/10.1088/1361-6595/aaa868.

[41] G. Giammaria, G. van Rooij, L. Lefferts, Plasma catalysis: distinguishing between thermal and chemical effects, Catalysts. 9 (2019) 185, https://doi.org/10.3390/ catal9020185.

[42] Y.R. Zhang, E.C. Neyts, A. Bogaerts, Influence of the material dielectric constant on plasma generation inside catalyst pores, J. Phys. Chem. C. 120 (2016) 25923-25934, https://doi.org/10.1021/acs.jpcc.6b09038.

[43] Q.Z. Zhang, A. Bogaerts, Propagation of a plasma streamer in catalyst pores, Plasma Sources Sci. Technol. 27 (2018) 1-10, https://doi.org/10.1088/1361-6595/aab47a 035009.

[44] K. Van Laer, A. Bogaerts, Influence of the gap size and dielectric constant of the packing material on the plasma behaviour in a packed bed DBD reactor: a fluid modeling study, Plasma Process. Polym. 14 (2017) 1-11 1600129 http://meetings. aps.org/Meeting/GEC16/Session/NW3.4.

[45] W. Wang, H.H. Kim, K. Van Laer, A. Bogaerts, Streamer propagation in a packed bed plasma reactor for plasma catalysis applications, Chem. Eng. J. 334 (2018) 2467-2479, https://doi.org/10.1016/j.cej.2017.11.139.

[46] P. Kasinathan, S. Park, W.C. Choi, Y.K. Hwang, J.-S. Chang, Y.K. Park, Plasmaenhanced methane direct conversion over particle-size adjusted MOx/Al2O3 (M = Ti and Mg) catalysts, Plasma Chem. Plasma Process. 34 (2014) 1317-1330, https:// doi.org/10.1007/s11090-014-9574-9.

[47] S. Jo, D.H. Lee, W.S. Kang, Y.H. Song, Effect of packing material on methane activation in a dielectric barrier discharge reactor, Phys. Plasmas 20 (2013), https:// doi.org/10.1063/1.4843875 123507-1 - 123507-8.

[48] A. Górska, K. Krawczyk, S. Jodzis, K. Schmidt-Szałowski, Non-oxidative methane coupling using $\mathrm{Cu} / \mathrm{ZnO} / \mathrm{Al} 2 \mathrm{O} 3$ catalyst in DBD, Fuel 90 (2011) 1946-1952, https:// doi.org/10.1016/j.fuel.2010.12.023.

[49] F.J.J. Peeters, M.C.M. Van De Sanden, The influence of partial surface discharging on the electrical characterization of DBDs, Plasma Sources Sci. Technol. 24 (2015) 015016, , https://doi.org/10.1088/0963-0252/24/1/015016.

[50] F. Peeters, T. Butterworth, Electrical diagnostics of dielectric barrier discharges, in: A. Nikiforov, Z. Chen (Eds.), Atmos. Press. Plasma - from Diagnostics to Appl. IntechOpen, 2018, pp. 1-27, , https://doi.org/10.5772/intechopen.80433.

[51] H.-H. Kim, Y. Teramoto, N. Negishi, A. Ogata, A multidisciplinary approach to understand the interactions of nonthermal plasma and catalyst: a review, Catal. Today 256 (2015) 13-22, https://doi.org/10.1016/j.cattod.2015.04.009.

[52] M. Dors, H. Nowakowska, M. Jasiński, J. Mizeraczyk, Chemical kinetics of methane pyrolysis in microwave plasma at atmospheric pressure, Plasma Chem. Plasma Process. 34 (2014) 313-326, https://doi.org/10.1007/s11090-013-9510-4.

[53] C. De Bie, B. Verheyde, T. Martens, J. Van Dijk, S. Paulussen, A. Bogaerts, Fluid modeling of the conversion of methane into higher hydrocarbons in an atmospheric pressure dielectric barrier discharge, Plasma Process. Polym. 8 (2011) 1033-1058, https://doi.org/10.1002/ppap.201100027.

[54] S. Kado, K. Urasaki, Y. Sekine, K. Fujimoto, T. Nozaki, K. Okazaki, Reaction mechanism of methane activation using non-equilibrium pulsed discharge at room temperature, Fuel. 82 (2003) 2291-2297, https://doi.org/10.1016/S00162361(03)00163-7.

[55] M. Scapinello, E. Delikonstantis, G.D. Stefanidis, A study on the reaction mechanism of non-oxidative methane coupling in a nanosecond pulsed discharge reactor using isotope analysis, Chem. Eng. J. 360 (2019) 64-74, https://doi.org/10.1016/j.cej. 2018.11.161. 